\title{
The Impact of Educational Expenditure on Ethiopian Economic Growth: Application of Vector Auto Regressive Model (VAR).
}

\author{
Bazezew Endalew \\ College of Business and Economics, Department of Economics, Addis Ababa University, Addis Ababa, Ethiopia
}

\begin{abstract}
This study has been attempted to investigate the fundamental impact of educational expenditure on the economic growth of Ethiopia. The nature of data was dynamic in nature and it covers the time ranges of 1975/76-2011/12, implies that the study adopts time series data analysis and the data was collected from secondary sources. To analyze the data, both descriptive and inferential approaches was utilized. The study employed the Solow growth model as a bench mark to specify the econometric model. The model was specified by considering real gross domestic product as a dependent variable subject to gross capital formation, labor force, educational expenditure, export and inflation as an independent variable. Both Vector Auto Regressive (VAR) and Vector Error Correction model was undertaken as an analytical procedure. The Augmented Dicky-Fuller (ADF) test was used to test the stationary nature of variables, so that all variables are stationary at level and first difference except inflation at its level form. The variables were co-integrated and confirmed the existence of long run interdependency. The result of the study was evaluated from both short run and long run aspects. It revealed that all variables were statistically significant except levels of export in the long run. Therefore, educational expenditure (our target variable), inflation and gross capital formation significantly and positively affects growth in long run aspects of the VAR system. However, labor force negatively affects growth. In the short run, only educational expenditure and inflation affects growth positively and significantly. Thus, the responsible bodies should be able to improve the level of investment in the educational sector and focus on skill and ingenuity to increase productivity at the margin.
\end{abstract}

Keywords: educational expenditure, stationary, impulse response, Vector Auto Regressive.

DOI: $10.7176 / \mathrm{JESD} / 11-21-02$

Publication date: November $30^{\text {th }} 2020$

\section{Introduction}

\subsection{Background of the Study}

Progress in education is vital. It induces people's understanding and observation of their environment. Well educated societies have an attempt to change their environment in accordance to their need. Education helps to develop some techniques and mechanisms to use and allocate the existing scarce resource effectively for the satisfaction of human wants and to develop the overall economic growth and development (Syed.,et al, 2017). Education is very crucial in the alternation of human behavior subject to different socio-economic factors. And also it helps to build up the individual personality, character, and intelligence and his productive capacity and ability to take his due place in economic and social activities in achieving the desired economic growth.

In General, education is a process whereby new knowledge is transmitted or acquired by man. However, the new knowledge must be perceived and it must alter future behavioral patterns. Economic growth depends to a large extent up on alternations in human behavioral patterns, because man is a good catalyst in the productive progress through his physical labor. Education involves a change in human behavior and is, therefore, crucial to economic growth both from the individual and the aggregate stand point (Anderson and Bowman, 1968).

Regarding the economic growth, for many years' people had the concept that educated and skilled labor force is a necessary condition of sustained economic growth. The contribution of education to economic growth is by creating a more productive labor force and ending it with increased knowledge and skill, providing widespread employment and income earning opportunities for teachers, social, construction workers, publishing workers and others; creating class of educated leaders to fill the space of others, promoting literacy and creating modernity (Todaro, 2006).

However, in spite of its significance, an efficient and optimal level of budget should be allocated so as to balance its contribution with economic growth; this is due to the fact that the extent of budget allocated to education may not guarantee its role to increase economic growth unless the system of education is able to crate the most skilled, innovative and productive personnel who are in a position to change his or her environment (Tsehaynesh, 2003).

According to the annual report of Ethiopian Minster of Finance and Economic Development (2014), although modern education was introduced in to a country about a century ago, it has yet to generate sufficient inertia to spearhead the nation's development. This failure is mainly due to capacity limitation to accommodate demand, increase in unemployment due to low investment, imbalance in educational investment (expenditure) and productivity, low education quality as well as the nature of the curriculum to the realities and development of the country observed on the ground. 
Modern education was introduced to Ethiopia nearly a century ago. However, the education and training offered during these long years had limited positive impact on the lives of the people and national development. The Education system offered has not enabled to solve the problems of farmers, pastoralist, and changes the lives of the over whelming majority of the people. During both the initial phase and its establishment the more planned and coordinated expansion of modern education after 1941, the primary objective of education in our country had been to produce trained man power that could run the emergent government bureaucracy. Particularly after 1941, the government's main concern was to replace expatriates that worked at various levels in office by Ethiopian national (CSA, 1994). As a result, the narrowed limited scale of formal education that existed, beyond incubating bureaucratic clears, had hardly any substantial merit. After a certain grade level, the ambition of the student population was largely to secure government employment than self-employment.

According to Ethiopian Ministry of Education report (2010), the level of educational government expenditure is continuously increased particularly from 2003/04 to 2007/2008 compared to the total government expenditure, according to the report, the growth rate of average annual education expenditure in this time range was about $22.6 \%$ compared to that of the annual average growth rate of total government expenditure which was about $19.6 \%$ it is larger by more than 3\%. However, it can be safely said that in all this long years, there was never as such a clear policy by which to evaluate and accordingly shape the direction of education and training along with its contribution to the economy in Ethiopia, subject to the level of expenditure.

\subsection{Statement of the problem}

Capital based on advanced technology, is no doubt an engine of growth, the human element is the determining factor not only in the formation of the capital itself, but also in transforming it to productivity, improving and sustaining it. Improving in the economic growth of Ethiopia has been considered to be attained by labor and capital alone and not by human development. In fact, it is the human resource development particularly the educational expansion; which is the major contributors to the economic growth of the country. Even labor and capital contribute a lot to economic growth; they themselves can do nothing (Smith, A, 1976). The implication is that, a certain level of human resource is needed to organize, combine, and efficiently utilize the available resources.

As far as Ethiopian experience is concerned, priority is manly given to grading and certification, rather priority is not given to quality and human capital development to get the fruits of education, this crates significant difficulty in the process of maintaining macroeconomic balance, which mainly arises from imbalance in annual educational budgeting and economic growth (Tsehaynesh, 2003).

Many empirical studies have been conducted to evaluate the impact of educational expenditure on economic growth. For instance, the findings of (Musila and Belassi, 2004; Wada and Kalakech, 2009; and Mekda., et al, 2014) revealed that educational expenditure have had a positive and long run significant impact on economic growth, whereas the large body of time series analysis of (Ndiyo, 2007; Nurudeen and Usman, 2010; and Irughe, 2013) found out that expenditure levels of education significantly and negatively affects economic growth in both the short run and long run analysis.

However, to the best of the researcher knowledge, in Ethiopia, no research of the same type was conducted in the past particularly on the educational expenditure impact on the economy by employing a dynamic annual time series data. Therefore, the fundamental question that this research was aimed to answer was, is really there is a direct association between educational expenditure and economic growth in Ethiopia?

Therefore, the general objective of the study was investigating the impact of educational expenditure on Ethiopian economic growth. Specifically, the researcher was attempted to answer the following objectives:

$\checkmark$ To investigate the extent at which educational expenditure affects economic Growth of Ethiopia.

$\checkmark$ To explore the short run relation between educational expenditure and economic growth.

$\checkmark$ To explore the long run relationship between educational expenditure and economic growth.

\section{Methodology of the study}

\subsection{Data types and sources}

The type of data employed in this study was a secondary one. It covers annual dates of Ethiopia from the time spans of 1975/76 to 2011/12. The data was collected from Ministry of Education Ethiopia, Ethiopian Ministry of Finance and Economic Development (MOFED), Central Statistical Office, Ethiopian Ministry of Labor and Social Affaire, annual conferences, journals, and proceedings.

\subsection{Methods of Data Analysis}

This study has been utilized both descriptive and econometric ways of data analysis. From the descriptive aspect, tables, graphs and proportions are employed as a tool of data analysis. The second and the most important approach of data analysis was the inferential one which adopts both Vector Auto Regressive (VAR) and Vector Error Correction (VEC) models as a process of extracting the optimal information of investigating the impact of educational expenditure on Ethiopian economic growth and other specific objectives. 


\subsection{Model Specification}

As far as this study is concerned, the outcome variable was a growth indicator, i,e the national Gross Domestic Product (GDP) registered over time in the study time horizons. Therefore, the Solow growth model was employed so as to specify the most aggregate variables affecting growth as supported by most macroeconomic theories (Solow, 1956). The basic model is formulated as:

$$
Y_{t}=A F(K, L)
$$

Where, $\mathrm{Y}$ is total domestic output at time t.

$\mathrm{K}$ is stock of capital (gross capital formation).

$\mathrm{L}$ is total active labor force.

A, is the level of technology, which is exogenously determined.

$Y_{t}$ refers real GDP at time t.

The above growth model could be extended to incorporate the relevant aggregate variables and to measure the impact of educational expenditure on economic growth. So that it was formulated as:

$$
Y_{t}\left(R G D P_{t}\right)=A K_{t}^{\beta 1} L_{t}^{\beta 2} \text { eduex }_{t}^{\beta 3} \text { export }_{t}^{\beta 4} \text { inf }_{t}^{\beta 5}+E_{t}
$$

Where, $R G D P_{t}$ is real gross domestic product that measures economic growth at time t.

$\mathrm{Kt}=$ gross capital formation at time $\mathrm{t}$

eduex $x_{t}=$ annual educational expenditure at time $\mathrm{t}$.

$L_{t}=$ labor force population at time $\mathrm{t}$.

export $_{t=}$ level of export at time $t$.

Inft is the level of inflation at time $t$.

$\beta_{1}, \beta_{2}, \beta_{3}, \beta_{4}$, and $\beta_{5}$, are elasticity parameters to be estimated.

$E_{t}$, is the residual term

We can re-write the equation by taking its natural logarisim we have;

$\ln Y_{t}\left(R G D P_{t}\right)=\ln \mathrm{A}+\beta_{1} \ln \mathrm{K}_{\mathrm{t}}+\beta_{2} \ln L_{t}+\beta_{3} \ln$ eduex $_{t}+\beta_{4} \ln \operatorname{export}_{t}+\beta_{5}$ inf $_{t}+E_{t}$

By differentiating this equation with respect to time we get,

$\ln Y_{t}\left(R G D P_{t}\right)=\alpha_{1}+\beta_{1} \ln \mathrm{K}_{\mathrm{t}} \beta_{2} \ln L_{t}+\beta_{3} \ln$ eduex $_{t}+\beta_{4} \operatorname{lnexport}_{t}+\beta_{5} \inf _{t}+E_{t} \ldots \ldots \ldots(4)$

\subsection{The Nature of Vector Auto Regressive and Vector Error Correction Models}

\subsubsection{Vector Auto Regressive (VAR) Model}

This model is mainly applicable when there are variables that their value is interlinked or interdependent one another under the specification of a given econometric model. The estimation of the parameters under the normal case of Ordinary Least Square (OLS) techniques provides biased and misleading outcomes (Gugrati,2004). When such problem is confronted under time series analysis, it is recommended to adopt a simultaneous equation model so as to resolve the endogenous bias of variables under consideration in the model.

However, to employ simultaneous equation model, we should be able to identify whether a given variable is endogenous or exogenous to the system, but in our case the variables were randomly undertaken as a factor of growth, this results identification problem. To overcome this problem, a VAR model is utilized because the model evaluates the variables from their common history point of view. So that it assumes constant mean, variance and covariance among the variables under consideration overtime, as a result, the model generates stationary time series results. Moreover, it assumes all variables as endogenous to the system due to the fact that the VAR technique express every endogenous variables as a function of its respective lags subject to the optimal lag length, this helps us no need of structural modeling. VAR is important because it is easy to estimate the vectors since it employs an OLS estimation technique.

\subsubsection{Vector Error Correction Model (VECM)}

The Vector Error Correction Model is a simple extension of the VAR, from which it is applicable when there are stationary variables in both short run and long run dynamics. As long as the variables in the VAR system experiences co-integration or attaining long run interdependence, then an error correction model is formulated to evaluate the long term interaction between variables. The model is relevant to show short run equilibrium of variables by restricting their achievement of long run equilibrium, it shows to what extent (magnitude) is the variables are inclined to achieve their long run equilibrium.

\section{Results and Discussions}

\subsection{Unit Root Test Analysis}

A standard classical method of estimation that are used in the applied time series economics work are based on a set of assumptions and one of which is the stationery of the time series variables. A time series data is Saied to be stationary if its mean and variance are constant over time and the value of covariance between time periods depends only on the disturbance or lag between the two periods and not the actual time at which the covariance is computed (Gujarati, 2004). If a time series is not stationary in the sense just defined it is called a non-stationary time series, 
then it will have a time varying mean and variance.

As Gujarati (2004) has noted, different methods can be used to test for the stationary of a series, but unit root test is the recently developed and widely used test of stationerity. Dickey -Fuller (DF) or Augmented Dicky-Fuller (ADF) tests are the most commonly techniques used to test for the existence of unit roots. In this study the variables of the model are tested for unit roots using ADF-test which augments DF test by lags of the dependent variable.

Table 1.1 Unit root test -ADF test statistics on RGDP

\begin{tabular}{|c|c|c|}
\hline Variables & ADF-I (0) & ADF-I (1) \\
\hline $\operatorname{lnRGDP}$ & $8.212 * * *$ & $2.702 * * *$ \\
\hline $\ln \mathrm{L}$ & $5.880 * * *$ & $3.691 * * *$ \\
\hline $\ln K$ & $4.709 * * *$ & $4.081 * * *$ \\
\hline lneduxp & $13.482 * * *$ & $3.220 * * *$ \\
\hline $\operatorname{lnInf}$ & -1.573 & $-7.572 * * *$ \\
\hline $\operatorname{lnExport}$ & $2.640 * *$ & $2.079 * *$ \\
\hline Critical values & & \\
\hline $1 \%$ & $2 . \overline{642}$ & -2.644 \\
\hline $5 \%$ & 1.950 & -1.950 \\
\hline $10 \%$ & -1.604 & -1.604 \\
\hline $\begin{array}{l}\text { refers } s t \\
\text { refers } s t\end{array}$ & $\begin{array}{l}\text { evel } \\
\text { evel }\end{array}$ & \\
\hline
\end{tabular}

Therefore, if the calculated t-statistics of the ADF value of the variables in absolute terms are greater than the respective critical values, then we are failed to accept the null hypothesis, this implies that the variables are stationary, or they are not unit root. In other words they experiences time invariant mean, variance and covariance, the converse is true if the calculated t-statistics of the ADF value of the variables in absolute terms are less than the respective critical values, then we are failed to reject the null hypothesis that the variables experiences nonstationary, i.e there is the problem of unit root. Accordingly, as we can see from table 1.1 above, all lagged values of the variables are stationary at level or integrated of order zero in the VAR system except annual inflation, whereas, at first difference all variables experience stationary.

\subsection{Tests for Co-integration}

An important issue in econometrics is the need to integrate short run dynamics with long run equilibrium. The analysis of short run dynamics is often conducted by first eliminating trends in the variable usually by differencing (Maddalla, 1992). In order to obtain both the short run dynamics and the long run relationships, one can appeal to what is known as co-integration. The interpretation of co-integration is two or more series are linked to form an equilibrium relationship spanning the long run, then even if the series are non-stationary, they will move together over time and the difference between them will be stationary (Verbeek, 2004). The test for co-integration is to test whether the residuals from the level regression are stationary. If these residuals are stationary, then the series are co-integrated. The level regression will then provide consistent estimate of the long run relationship.

In time series inferential analysis, there are two major procedures to test for the existence of co-integration (the Engle-Granger two steep procedures and the Johannes maximum like hood estimation procedure). However, the study used the Engle-Granger two step procedures as a means of testing for co-integration in the VAR system. Here, the variables entering the co-integrating vector are tested for integration of the same order. The first step is to estimate the long run static model of the same level of integrated variables and obtain the residual. If this residuals, which is the linear combination of the variables are side to be co-integrated, then they do have long run relationship. The second steep in this procedure is to estimate the error correction model (ECM). This will allow us to estimate the dynamic model using differenced variables where the coefficients of the lagged residual will be the deviation from the long run relationship (Maddala, 1992). This study has been followed the Engle-Granger (EG) approach to perform the co-integration test using ADF test statistics. And then the residual from the long run model is tested for its stationarity; and it is found that the residual is stationery at level (at $1 \%, 5 \%$, and $10 \%$ critical values), which are shown in the table below. The fact that the residual is stationery implies that the variables are co-integrated or there exists a long run equilibrium relationship among the variables of the model in the VAR system. 
Table1.2 Co-integration ADF test statistics of the residual term

$\begin{array}{lll}\text { ADF test statistics } & 1 \% \text { critical value } & 5 \% \text { critical value } 10 \% \text { critical value }\end{array}$

\begin{tabular}{ccc}
\hline $6.710^{* * *}-2.642$ & 1.950 & -1.604 \\
\hline \hline$* * *=$ stationery at $1 \%$ & & \\
\hline
\end{tabular}

Now from table 1.2 above, the residual or the error term of the time series are stationery at level. This shows that there is long run equilibrium relationship between the variables, that is the stationarity of the residual at level shows that the regression results are not spurious.

\subsection{Diagnostic Tests:}

To confirm the regression results are efficient and unbiased for interpretation, it is advisable to test the most usual OLS assumptions (Verbeek, 2004). Therefore, the conditional distribution of residual terms conditional to the regression matrix should have zero mean and constant variance (homoscedastic). So that, the study has been employed the Breusch Pagan/Cook-Weisberg test for hetroscedasticity, and it validate the existence of hetroscedasticity problem, because we are failed to accept the null hypothesis of constant variance at a $5 \%$ significance level. However, to overcome the problem a robust regression was running.

The problem of mullticolinearity arises when there is a significant interdependence among independent variables included in a given econometric model; when this problem is confronted, the estimated vectors will provide an unreliable output (Verbeek, 2004). So that the average Variance Inflation Factor (VIF) of independent variables our time series model was about 11.02, which is less than ten (10) -the standard and statistically acceptable value of mullticollinearity test in most time series analysis (Gujarati N, 2004).

To prove out whether the model is correctly specified or not, the Ramsey RESET test technique of omitted variable problem was employed. Therefore,

$H_{o}$ : Model has no omitted variables

Prob $>F=0.0501$. Therefore, the $\mathrm{p}$-value of $0.0501>0.05$ ( $\mathrm{sig}$ level), we failed to reject the null hypothesis; hence the model is correctly specified.

To verify the existence of serial correlation between stochastic terms in the model, the Durbin Watson (DW) test technique was used, i.e if the DW tests value is above two in time series analysis, it confirms no autocorrelation(Gujarati N, 2004), so that our DW value is about 2.34.

\subsection{Long Run Analysis of the Growth Model}

Once the verification of co-integration is done, the next step is estimating the growth model and evaluates the dynamic impact of educational expenditure on Ethiopian economic growth, which is used as a proxy of measuring the role of education to growth processes. Similarly, the effect of other aggregate variables (capital formation, export, inflation, and labor force) on economic growth or annual real gross domestic product (RGDP) was also explored under the system.

Table 1.3 Estimation results of the long run model (Dependent variable; Lnrgdp)

\begin{tabular}{l|l|l|l|l|}
\hline \hline Variable & Coefficient & Std.error & t-statistic & t-probability \\
\hline $\ln L$ & -0.3174704 & 0.2841333 & -1.12 & $0.0272^{* *}$ \\
\hline $\operatorname{lnK}$ & 0.2806332 & 0.1260959 & 2.23 & $0.033^{* *}$ \\
\hline Lneduex & 0.6133636 & 0.1431462 & 4.28 & $0.000^{*}$ \\
\hline Inf & 0.0069144 & 0.0021745 & 3.18 & $0.003^{*}$ \\
\hline Lnexport & 0.0464647 & 0.0558748 & 0.83 & 0.412 \\
\hline Constant & 4.132337 & 0.6228936 & 6.63 & $0.000^{*}$ \\
Number of observation & $=37$ & $*=$ significant at $1 \%$ & \\
F $(5,31)$ & $=1043.31$ & $* *=$ significant at 5\% \\
Prop $>$ F & $=0.0000$ & Degree of freedom $=0.05$ & \\
R-squared & $=0.924$ & Root MSE $=0.10002$ & \\
Adjusted R-squared & $=0.9131$ &
\end{tabular}

As we can observe from table 1.3 above, the model is jointly significant at $1 \%$ (Prop $>\mathrm{F}=0.0000$ ) level of critical value. Moreover, from individual significance point of view, gross capital formation and labor force were statistically significant at 5\% level of significance, while educational expenditure, level of inflation and the constant term were statistically significant at $1 \%$ level of significance.

Therefore, our target variable, which is educational expenditure that measures the contribution of education to economic growth, shows that ceteris paribus as the annual educational expenditure increases by one Ethiopian birr, on average the national real GDP increases by 0.62 units, it has a very crucial positive effect on economic 
growth. The implication is that as the government allocates budget to the educational sector overtime, it increases the number of graduates from universities and colleges, this crates educated man power and then surplus labor force for both the financial and capital sector of the economy, eventually the economy would be bolstered (Harbison, 1973). Moreover, if the economy generates educated human power, then it directly increases the health status of the population and educational quality, this intern crates high levels of domestic saving in the nation because of the fact that educated societies are likely to be aware of the importance of saving and investment, and also they are in a position to know the risk and return characteristics of assets through forecasting the existence of unforeseen events in this uncertain real world feature. This finding is consistent with the findings of (Musila and Belassi, 2004; Wada and Kalakech, 2009; and Mekda., et al, 2014) who found out the positive and significant impact of educational expenditure on economic growth.

However, the sign of variables like annual average inflation and labor force are not consistent with their expected sign although there time series relation is statistically significance according to the model. So that ceteris paribus, a one unit increase in labor force reduces the national output by 0.31 units (how?) this might be due to, labor force is the component of employed and unemployed working force population, hence, as long as the number of unemployed working force population increases following the unavailability of job opportunity and whatever reason, affects the national output growth negatively. On the other hand, although there are peoples who are employed, their marginal productivity may be inefficient due to their low level of skills and indignity embodied on the labor force. As a result of this problem of knowledge and skill gaps, workers are unable to utilize the scarce resource in an efficient and appropriate manner. Consequently, this underutilization of the countries scarce resource leads to a deterioration of the national output (Musila and Belassi, 2004 ).

Analogously, the annual average inflation is expected to have a negative impact on economic growth, but according to the estimated model, inflation positively affects economic growth, that is, ceteris paribus, a one unit increase in annual average inflation, on average bolsters economic growth by 0.0067 unit, because a moderate level of inflation is very important to intensify the level of investment generated in the country. This forces firms to hire higher number of workers and paying higher amount of wages, it also intern improves the income of the employee. This improvement of income not only increases the income of the employed but also it attracts those who are out of the labor market, and then employment will increase, real output will increase and the economy becomes grow (Wada and Kalakech, 2009). In general, from this long -run model we can understand that the annual educational expenditure contributes larger amount of real output growth and also gross capital formation and export (not statistically significant) contributes $28 \%$ and $4.6 \%$ respectively.

\subsection{Short Run Analysis of the Growth Model}

\subsubsection{The Vector Error Correction Model (VECM)}

To explain the short run relationship between independent and dependent variables that are co-integrated in the long run, we should restrict the VAR system as it is not stationary in the short run or we assume disequilibrium in the short run. As a result, the residual of the long run model can be treated as the equilibrium residual and it can be used to connect the short run behavior of the dependent variable to its long run value. The ECM is also important since it conveys information for the speed of adjustment for short run disturbance to long run equilibrium. If the variables are stationary, say, at first difference, the short run model, ECM can be specified as:

\section{XRGDP $_{t}=\alpha_{0}+\alpha_{1} A_{x_{t}+} \mathbf{U}_{t-1}+\mathrm{e}_{\mathrm{t}}$}

Where, et is the white noise, A is the first difference and Ut-1 is the one year lagged of the long run residual value. The short run model relates Yt to change in Xt and the lagged equilibrium error term, Xt represents the short run disturbance in Yt, and $\boldsymbol{\alpha}_{\mathbf{1}}$ represents the speed of adjustment towards the long run equilibrium.

\subsubsection{Discussion of the Short-run results}

The short run regression equations can be estimated by Engel-Granger two stages procedure .In the above case, the long run relationship between dependent and independent variables are established .In this section the error correction model is estimated to determine the coefficients of the short run dynamics and to grasp how fast the disturbance in the short run coefficients adjust to their long run value. The estimation result of the short run model is presented below. 
Table 4.4 Estimation results of the short run model dependent variable; Lnrgdp

\begin{tabular}{|c|c|c|c|c|}
\hline Variable & coefficient & std error & t-statistic & t-probability \\
\hline u_01 & -0.1985512 & 0.1423772 & -1.39 & $0.0174^{* *}$ \\
\hline dlnL & -0.6233676 & 0.38888084 & -1.60 & 0.120 \\
\hline $\operatorname{dlnK}$ & 0.1018788 & 0.1000132 & 1.02 & 0.317 \\
\hline dlneduexp & 0.533146 & 0.191286 & 2.79 & $0.009^{*}$ \\
\hline dlnexport & 0.0795259 & 0.058155 & 1.37 & 0.182 \\
\hline $\operatorname{dinf}^{1}$ & 0.0047968 & 0.0014813 & 3.24 & $0.003^{*}$ \\
\hline constant & 0.0443239 & 0.0292511 & 1.52 & 0.141 \\
\hline \multirow{6}{*}{$\begin{array}{l}\text { Number of observation } \\
\text { F }(6,31) \\
\text { Prob }>\text { F } \\
\text { R-squared } \\
\text { Adj R-squared }\end{array}$} & $=37$ & Root MSE & \multicolumn{2}{|c|}{$=0.0424$} \\
\hline & $=6.59$ & Dws & \multicolumn{2}{|c|}{$=2.413646$} \\
\hline & $=0.0002$ & Chi2 (1) & \multicolumn{2}{|c|}{$=0.12$} \\
\hline & $=0.5768$ & Prob $>$ chi 2 & \multicolumn{2}{|c|}{$=0.7247$} \\
\hline & $=0.4892$ & $* *$ & \multicolumn{2}{|c|}{$=$ significant at $5 \%$} \\
\hline & & $*$ & \multicolumn{2}{|c|}{$=$ significant at $1 \%$} \\
\hline
\end{tabular}

From table 4.5, we can understand that the coefficient of the stochastic term is statistically significant at $5 \%$ significance level. The important thing that forces to conduct the error correction model (ECM) is that, although the variables of the model are co-integrated, there may be disequilibrium in the short run dynamics. Thus, the coefficient of the lagged residual tells us; about $20 \%$ of the short run disequilibria of real gross domestic product of the growth model is adjusted or converged to its long-run equilibrium. It is the extent at which the dependent variable is prevented to reach in its long run equilibrium dynamics. Or ceteris paribus, on average, about $0.54 \%$ of the short-run disequilibrium of the model (Ethiopian RGDP) is adjusted or converged in every year (within 37 years of the sample).

On the other hand, in the short run analysis of the growth model, only educational expenditure and inflation are statistically significant at 5\%, their directional impact on Ethiopian RGDP is consistent with their long run counter parts. However, the extent of impact on growth in both cases (educational expenditure and inflation) is lower in the short run than the long run dynamics. The probable reason is that when we invest on education overtime, our human resource will be increased as well, plus the lower level educated persons will be able to upgrade themselves in the long run because of educational expansion, this will in turn improves their skill and ability to run and utilize resources, i.e higher marginal productivity and increase economic growth.

Similarly, the positive impact of inflation is higher in the long run (0.006) than the short run (0.004) dynamics. This is because when there is moderate and consistent level of inflation in the economy, it is used as a fuel or best catalyst towards the economy by creating more investment resulting from lower supply of goods and services in the economy, higher demand of labor, higher wage, higher employment and high productivity (Nurudeen and Usman, 2010).

\subsection{Impulse Response Analysis}

The novel concept in time series research is an impulse response analysis. This technique is helps to detect the statistical impact of a given standard deviation shock (it may be positive or negative) in one of our regressors in the VAR system on our response variable or real gross domestic product (RGDP). It tells by how much the total value of the response variable is responsive (RGDP in our case) on that standard deviation shock of the independent variable subject to different time periods in our restricted sample.

Therefore, as we can see from table 3.5 below, at the first period a one unit standard deviation shock of Ethiopian educational expenditures increases the total amount of RGDP by about $0.0003 \%$, whereas a one unit standard deviation shock of the other independent variable at the first period makes the total value of RGDP no responsiveness at all. In the second period however, a one unit standard deviation shock of all independent variables have had a different proportional impact on growth value at different periods. The important thing what we observe here is that a shock in educational expenditure and inflation have consistent increment in growth discussed so far in the short and long term dynamics of the VAR system.

\footnotetext{
${ }^{1}$ The optimal lag length of the model was checked by Akaike information criterion. It was found to be one.
} 
Table 3.5 Impulse Response Analysis on RGDP

\begin{tabular}{lccccc}
\hline \hline Period & Incapital & Inlabor & Ineduexpend & Inexport & Ininfila \\
\hline 1 & 0.0000 & 0.0000 & 0.0003 & 0.0000 & 0.0000 \\
2 & 0.0341 & -0.0862 & 0.0032 & 0.0002 & 0.0012 \\
3 & 0.0327 & -0.0822 & 0.0462 & 0.0031 & 0.0013 \\
4 & 0.0321 & -0.0091 & 0.0038 & 0.0034 & 0.0015 \\
5 & 0.0038 & -0.0081 & 0.0542 & 0.0053 & 0.0032 \\
6 & 0.0027 & -0.0893 & 0.0574 & 0.0056 & 0.0036 \\
7 & 0.0024 & -0.0062 & 0.0732 & 0.0021 & 0.0072 \\
8 & 0.0041 & -0.0058 & 0.0876 & 0.0034 & 0.0760 \\
9 & 0.0021 & -0.0073 & 0.0834 & 0.0065 & 0.0124 \\
10 & 0.0011 & -0.0003 & 0.0931 & 0.0245 & 0.0253
\end{tabular}

value relative to others, this is an indication of how both variables impacting growth in the long run as we have

\section{Conclusions and Recommendations \\ 4.1 Conclusions}

The major objective of this study was to investigate the impact of educational expenditure on Ethiopian economic growth. The study used dynamic annual data (1975/76-2011/12) of major aggregate variables that affect economic growth, implies the data was secondary in nature. The Solow growth model was used as a bench mark so as to analyze economic growth and specify our econometric model at the initial stage. The technique of both Vector Auto Regressive and Vector Error Correction model was utilized so as to capture the problem of endogenous bias and structural modeling to get the most optimal and reliable inferential result with a minimum loss of information. Moreover, the two principal models are crucial to evaluate both the long run and short run equilibrium of the series.

The stationary nature of variables was evaluated with the system of unit root by using the Augmented Dikey Fuller (ADF) test technique, the result revealed that all the variables were stationary at level except inflation, but it was stationary at first difference or integration of order one I(1). To verify the existence of long run interdependence of variables, the method of co-integration was adopted. To run this analysis, the Engle-Granger two stage procedures were employed. Firstly, the stationary characteristics of the stochastic term was verified to be sure that the long run equilibrium of the VAR system is constrained by the residual terms of the model, secondly, the error correction model was conducted to capture the extent at which the short run disequilibrium is converged to long run equilibrium, therefore about $20 \%$ of the disequilibrium of the response variable or economic growth is adjusted to its long run equilibrium in our sample period.

The estimated result of the long run growth model revealed that all variables except export rate were found to be statistically significant. Educational expenditure, which is our target variable of affecting growth, was positively affects growth by about 0.61 . Similarly, gross capital formation and inflation rate affects growth positively and significantly by 0.28 and 0.0069 respectively. However, labor force negatively affects growth in the long run but not statistically significant in the short run. In the short run only educational expenditure and inflation affects growth positively and statistically, the extent of their short run impact is lower than that of the long run. To evaluate the responsiveness of the total value of real gross domestic product when there is a one standard deviation shock in any of the independent variable, the researcher was in a position to conduct an impulse response analysis of the growth model. Accordingly, at the first period, the total value of RGDP is responsive only for a one standard deviation shock in educational expenditure, but it is responsive for other variable shocks at different time periods. This analysis indirectly confirms the dynamic interaction of variables and their extent of impact.

\subsection{Recommendations}

$\checkmark$ As the result of the study reveals educational expenditure positively affects growth, therefore, the government should be invest on education particularly on skills and attitudinal change so as to run innovated systems of production

$\checkmark$ The government should also aware of the society about the crucially of the educational sector on the area of ensuring cultural revolution and the creation of development oriented attitudes through training and experience to adopt improved way of technologies apart from the mere nature of certification.

$\checkmark \quad$ Labor force negatively affects growth mostly in the short run, this may shows that the surplus labor force is not efficiently (under) utilized in the Ethiopian economy or it may indicate lower marginal productivity, so that improvements should be done to balance the labor market and productivity at the margin.

\section{Refference}

Anderson, A and Bowman, M .(1968). The Role of Education in Development. ALDINE published compuny, New york . 
Blaug,M. (1972): Introduction to the economics of education, Harmondsworth,London.

Dension,E.(1967). Sources of Economic Growth in the United States and the Alternative before United States. Supplementary paper no.13,New York, committed for economic development.

Ethiopian Central Statistical Agency Report. (1994). Addis Ababa, Ethiopia.

Ethiopian education and Training Policy. (April, 1994)

Fagerlind, A and Saha, L. (1997). Education and National Development. Red educational and Professional Publishing ltd, New, Delhi.

Gujarati. (2004). Basic Econometrics, fourth edition, rata Mc Graw-Hill,New Delhi.

Harbison, P.H(1973); Human Resource and The Wealth of Nations ,New York ;Oxford

Iruhhe, I. (2013). The Impact of Educational Expenditure on the Economic Growth of Nigeria. Vector Error Correction Specification. The Social Science 8(2); 206-212, 2013.

Jeffrey, K. (2018). Education expenditure and economic growth: Some Empirical Evidence from Côte d'Ivoire. Online at https://mpra.ub.uni-muenchen.de/88350/MPRA Paper No. 88350.

Maddala, G.(1992). Econometrics, University of Horida.

Mekdad, Y., Dahmani, A., \& Louaj, M. (2014). Public spending on education and Economic Growth in Algeria: Causality Test. International Journal of Business and Management, 2(3), 5570.

Ministry of Education Annual Abstract. (2010). Addis Ababa, Ethiopia.

Ministry of Finance and Economic Development Report. (2014). Addis Ababa, Ethiopia.

Musila, J. W., \& Belassi, W. (2004). The Impact of Education Expenditures on Economic Growth in Uganda: Evidence from Time Series Data. The Journal of Developing Areas, 38(1), 123-133.

Ndiyo, N. A. (2007). A Dynamic Analysis of Education and Economic Growth in Nigeria. The Journal of Developing Areas, 41(1), 1-16.

Nurudeen, A., \& Usman, A. (2010). Government expenditure and economic growth in Nigeria (1970-2008): A disaggregated analysis. Business and Economics Journal, 2, 1-11.

Schultz T.(1981). Investing in people; The Economics of Population Quality; University of California press.

Schumpeter, J.(1973). The theory of Economic Development Cambrage Mass Harvared University press.

Smith, A.(1976). An enquiry in to the nature and causes of the wealth of nations.Chicago ,University of Chicago press.

Solow and Obert M.(1956). A contribution to the theory of economic growth. The quarterly journal of economics. Syed K.,Omayma K., and Shumaila W.(2017). Impact of Education Expenditure on the Economic Development. An Empirical Investigation in Case of Kuwait. International Journal of Management Sciences and Business Research, Nov-2017 ISSN (2226-8235) Vol-6, Issue 11http://www.ijmsbr.comPage 90.

Tehayagnesh, A. (2003). The Impact of Education on the Economic Growth of Ethiopia. Addis Ababa, Ethiopia. Todaro, P. Economic Development in third world 9 ${ }^{\text {th }}$ edition, New york University, 1994.

United Nation Human Development Report, 2001.

Wadad, S., \& Kalakech, K. (2009). The Nature of Government Expenditure and its Impact on Sustainable Economic Growth. Middle Eastern Finance and Economics, 39(45), 39-45. 